\title{
CFD and kineticbased modeling to optimize the sparger design of a largescale photobioreactor for scaling up of biofuel production
}

DOI:

10.1002/bit.27010

\section{Document Version}

Accepted author manuscript

Link to publication record in Manchester Research Explorer

Citation for published version (APA):

Ali, H., Solsvik, J., Wagner, J. L., Zhang, D., Hellgardt, K., \& Park, C. W. (2019). CFD and kineticbased modeling to optimize the sparger design of a largescale photobioreactor for scaling up of biofuel production. Biotechnology and Bioengineering. https://doi.org/10.1002/bit.27010

Published in:

Biotechnology and Bioengineering

\section{Citing this paper}

Please note that where the full-text provided on Manchester Research Explorer is the Author Accepted Manuscript or Proof version this may differ from the final Published version. If citing, it is advised that you check and use the publisher's definitive version.

\section{General rights}

Copyright and moral rights for the publications made accessible in the Research Explorer are retained by the authors and/or other copyright owners and it is a condition of accessing publications that users recognise and abide by the legal requirements associated with these rights.

\section{Takedown policy}

If you believe that this document breaches copyright please refer to the University of Manchester's Takedown Procedures [http://man.ac.uk/04Y6Bo] or contact uml.scholarlycommunications@manchester.ac.uk providing relevant details, so we can investigate your claim.

\section{OPEN ACCESS}




\section{1}

\title{
CFD and kinetic-based modelling to optimize the sparger design of a large-scale photobioreactor for scaling up of biofuel production
}

\author{
Haider Ali ${ }^{1,2,3}$ and Cheol Woo Park ${ }^{1 \dagger}$ \\ ${ }^{1}$ School of Mechanical Engineering, Kyungpook National University, 80 Daehakro, Bukgu, \\ Daegu, 41566, Korea \\ ${ }^{21}$ Department of Chemical Engineering, Imperial College London, South Kensington Campus, \\ London SW7 2AZ, UK \\ ${ }^{3}$ Department of Chemical Engineering, Norwegian University of Science and Technology \\ (NTNU), Trondheim, NO-7491, Norway \\ ${ }^{\dagger}$ Corresponding author: Cheol Woo Park: Tel.: +82 (53) 950 7569; Fax: +82 (53) 9506550 ; \\ Email: chwoopark@knu.ac.kr
}

\section{Abstract}

Microalgal biofuels have not yet achieved wide-spread commercialization, partially as a result of the complexities involved with designing and scaling up of their biosystems. The sparger design of a pilot-scale photobioreactor $(120 \mathrm{~L})$ was optimized to enable the scale-up of biofuel production. An integrated model coupling computational fluid dynamics and microalgal biofuel synthesis kinetics was used to simulate the biomass growth and novel biofuel production (i.e. bisabolene) in the photobioreactor. Bisabolene production from Chlamydomonas reinhardtii mutant was used as an example to test the proposed model. To select the optimal sparger configuration, a rigorous procedure was followed by examining the effects of sparger design parameters (number and diameter of sparger holes and gas flow rates) on spatially averaged bubble volume fraction, light intensity, friction velocity, power input, biomass concentration, and bisabolene production. The optimized sparger design increases the final biomass concentration by $18 \%$, thereby facilitating the scaling up of biofuel production. 
Keywords: biofuel, photobioreactor, scale-up, sparger design, CFD, kinetic modelling

\section{Introduction}

The global shift toward biomass-based renewable energy continues rapidly because of its sustainability and low environmental impact. Microalgae serve as the primary biomass source, with a production rate remarkably higher than those of other plant crops. Closed photobioreactors (PBRs) are one of the practical systems used for mass microalgal cultivation. PBRs prevent water evaporation and contamination with efficient temperature control and excellent light utilization (Chisti, 2007). Gas sparging is the most important factor to design and scale-up PBRs successfully because it directly affects mixing and light utilization (Gupta et al., 2015; Singh and Sharma, 2012). A sparger is used for bubbling gas from the bottom of the PBR to mix and degas the culture. The selection of the gas sparger is process specific, and to date, different types of spargers have been proposed, such as perforated plate, ring, and pipe. However, the type of sparger exhibits no significant difference in the hydrodynamic properties of the PBR (Luo et al., 2011). Gas sparging of the PBR remarkably depends on the inlet gas flow rates, frictional losses, algal biofouling, and the geometrical design parameters of the sparger (number, diameter, location, and orientation of holes). An increase in gas sparging rate enhances the mixing and degassing of culture in the PBR (Zhang et al., 2002). Nevertheless, increasing the gas sparging rates produces a large number of gas bubbles in the PBR, resulting in increased bubble scattering and reduced light utilization. Changing the number and diameter of sparger holes affects the liquid movement and mass transfer in the PBRs (Zhang et al., 2002; Zhang et al., 2015b). Gas bubbling in the PBR requires considerable power. The power input for gas bubbling depends on the inlet gas flow rates and pressure drop in the PBR. High sparging rates consume substantial power, making them infeasible for large-scale biomass production. Design parameters and biofouling of the sparger also 
48 affect the power input because of their significant influence on the pressure drop (Béchet et al., 49 2013a; Chisti, 1998; Kulkarni et al., 2007).

50 Sparger-induced mixing ensures rapid transfer of $\mathrm{CO}_{2}$ and nutrients, cell sedimentation prevention, 51 uniform $\mathrm{pH}$ maintenance, and efficient gas exchange between microalgae culture and air (Carvalho 52 et al., 2006; Luo and Al-Dahhan, 2004). Rapid mixing along the light penetration path enhances 53 the photosynthetic efficiency of PBR by shifting algal cells between the light/dark cycles (Sforza et 54 al., 2012). However, microalgal cells are sensitive to fluid dynamic stresses. Intensive mixing can 55 cause shear-induced damage to these cells and consequently reduce their biomass productivity 56 (Leupold et al., 2013; Michels et al., 2016; Thomas and Gibson, 1990). In addition to the bubble 57 rising and bursting phenomena in the $\mathrm{PBR}$, the bubble formation at the sparger could also damage 58 algal cells (Barbosa et al., 2004). Shallow cultures utilize light more efficiently than dense cultures 59 because of reduced light attenuation. Therefore, the scaling up of PBRs requires careful consideration of light attenuation, which is the decrease in local light intensity along the light

61 penetration direction in the PBR. Light attenuation depends on the wavelength, PBR geometry, and 62 light penetration distance. This result suggests that the local light intensity is significantly affected 63 with microalgal cells concentration, gas bubble scattering, and light absorption by microalgal cells. 64 Therefore, numerous PBR designs have been developed to increase light utilization by reducing 65 the effects of gas bubble scattering and cell light absorption (Berberoglu et al., 2007; Fernandes et 66 al., 2010; Molina Grima et al., 1994; Posten, 2009).

67 Advancements in the computational fluid dynamics (CFD) tools enable the modelling and 68 improvement of biofuel production in industrial PBRs. A number of studies have been conducted 69 to improve the PBR mixing by using baffles and specially designed mixers. Nonetheless, most of 70 these studies focused only on the hydrodynamic or light regime characteristics of laboratory-scale 
71 PBRs (less than $10 \mathrm{~L}$ ), without including microalgal growth and biofuel production in their CFD 72 models (Bergmann and Trösch, 2016; Chen et al., 2016; Huang et al., 2014; Huang et al., 2015; Su

73 et al., 2010; Sun et al., 2016; Yang et al., 2016). Moreover, despite the importance of gas sparging 74 in the design and scale-up of PBRs, only a few studies were conducted to investigate the influence 75 of sparger design on mixing and light transmission in laboratory-scale PBRs (1 L) (Ranade and 76 Tayalia, 2001; Zhang et al., 2015b). CFD modelling of hydrodynamics and growth kinetics 77 (microalgae growth and biofuel production) in a large-scale PBR involves multiple scales, making 78 it a highly complex and challenging task. Consequently, previous studies have been limited to 79 investigating hydrodynamics and growth kinetics for large-scale cultures.

80 To fill this gap, the present study primarily aims to develop a hybrid model including CFD and

81 microalgal growth kinetics to optimize the sparger design of a pilot-scale PBR (120 L) for 82 scaling up of biofuel production. The biomass growth and biofuel (i.e. bisabolene in this study) 83 production from Chlamydomonas reinhardtii were estimated with consideration of the influence 84 of different sparger design parameters. A genetically modified C. reinhardtii strain was used to 85 produce excreted biofuel (i.e. bisabolene in this study (del Rio-Chanona et al., 2019; Wichmann 86 et al., 2018)). Results of the CFD model were validated using experimental results of biomass 87 concentration and bisabolene production. Sparger design was optimized by analyzing and 88 determining the effects of sparger design parameters (number and diameter of sparger holes and 89 gas flow rates) on spatially averaged bubble volume fraction, light intensity, friction velocity, 90 power input, biomass concentration, and bisabolene production. The loss in PBR productivity 91 related to shear-induced cell damage (dead zones) was also taken into account. An empirical 92 correlation was specifically developed to estimate the bubble volume fraction using the sparger 
93 design parameters in large-scale PBRs, with consideration of effects of bubble scattering on the

94 local light intensity.

\section{2. Mathematical modelling}

96 The CFD model of the 120 L pilot-scale flat-plate PBR (Department of Chemical Engineering of

97 Imperial College London, UK) was constructed and is shown in Figure 1. The liquid 98 compartment contains the microalgal culture; its dimension shows a width $(W)$ of $1700 \mathrm{~mm}$, 99 height $(H)$ of $900 \mathrm{~mm}$, and depth $(D)$ of $67 \mathrm{~mm}$. A sparger (diameter $=20 \mathrm{~mm}$ and width $=1600$ $100 \mathrm{~mm}$ ) is used to inject recycling gas into the liquid compartment from the bottom of the PBR to 101 mix the culture and supply $\mathrm{CO}_{2}$. A full factorial design $\left(2^{3}\right)$ was implemented to generate eight 102 possible design configurations of the sparger based on the number and diameter of sparger holes 103 and recycling gas flow rates (Table 1). It is noticeable that once the number of holes was 104 determined, the hole pitch was also fixed automatically in this study, given the assumption that 105 holes are evenly distributed on the sparger surface. The present study assumed that the microalgal 106 cell movement is approximately same as the bulk movement of liquid because of the negligible 107 difference between liquid and biomass densities (Zhang et al., 2015b). Therefore, the gas bubbles 108 rising from the PBR bottom induce a circulatory motion in the liquid culture because of the 109 buoyancy effect; this phenomenon represents a two-phase gas-liquid flow mixing problem (Becker 110 et al., 1994).

\section{$111 \quad$ 2.1. Hydrodynamic modelling}

112 The Euler-Euler method solves the average phase concentrations; thus, it was used to model the 113 gas-liquid flow in the PBR (Becker et al., 1994; Lestinsky et al., 2012). The continuity equations 114 for liquid and gas phases are expressed as follows: 
$115 \frac{\partial}{\partial t} \varphi_{l} \rho_{l}+\nabla\left(\varphi_{l} \rho_{l} U_{l}\right)=0$

$116 \frac{\partial}{\partial t} \varphi_{g} U_{g}+\nabla\left(\rho_{g} \varphi_{g} U_{g}\right)=\mathrm{m}_{\mathrm{gl}}$

117 where $\varphi_{l}$ is the liquid volume fraction (1), $\rho_{l}$ is the liquid density $\left(\mathrm{kg} / \mathrm{m}^{3}\right), U_{l}$ is the liquid 118 velocity $(\mathrm{m} / \mathrm{s}), \varphi_{g}$ is the gas bubble volume fraction (1), $U_{g}$ is the gas velocity $(\mathrm{m} / \mathrm{s}), \rho_{g}$ is the 119 gas density $\left(\mathrm{kg} / \mathrm{m}^{3}\right), \nabla$ is the gradient operator $\left(\frac{\partial}{\partial x}, \frac{\partial}{\partial y}, \frac{\partial}{\partial z}\right)$, and $\mathrm{m}_{\mathrm{gl}}$ is the interfacial mass transfer 120 rate $\left(\mathrm{kg} / \mathrm{m}^{3} \cdot \mathrm{s}\right)$. The gas bubble volume fraction or holdup is the total volume of gas retained in 121 the PBR at a given time. The governing equations of the momentum for liquid and gas phases are 122 as follows:

$123 \frac{\partial}{\partial t}\left(\varphi_{l} \rho_{l} U_{l}\right)+\nabla\left(\varphi_{l} \rho_{l} U_{l} U_{l}\right)=-\varphi_{l} \nabla p+\nabla \cdot \varphi_{l}\left[\mu_{l}\left(\nabla U_{l}+\left(\nabla U_{l}\right)^{T}\right)\right]+\varphi_{l} \rho_{l} \mathrm{~g}$

$124 \frac{\partial}{\partial t}\left(\varphi_{g} \rho_{g} U_{g}\right)+\nabla\left(\varphi_{g} \rho_{g} U_{g} U_{g}\right)=-\varphi_{g} \nabla p+\nabla \cdot \varphi_{g}\left[\mu_{g}\left(\nabla U_{g}+\left(\nabla U_{g}\right)^{T}\right)\right]+\varphi_{g} \rho_{g} \mathrm{~g}$

125 where $p$ is the pressure (Pa), $\mu_{l}$ is the liquid dynamic viscosity (Pa.s), $\mathrm{g}$ is the gravity vector $126\left(9.81 \mathrm{~m} / \mathrm{s}^{2}\right)$, and $\mu_{g}$ is the gas dynamic viscosity $(\mathrm{Pa} \cdot \mathrm{s})$. Liquid volume fraction $\left(\varphi_{l}\right)$ and gas 127 velocity $\left(U_{g}\right)$ are defined as follows (Sokolichin et al., 2004):

$128 \varphi_{l}=1-\varphi_{g}$

$129 U_{g}=U_{l}+U_{\text {slip }}$

130 where $U_{\text {slip }}$ represents the slip velocity $(\mathrm{m} / \mathrm{s})$. The Euler-Euler model uses the following 131 equations to calculate slip velocity $\left(U_{\text {slip }}\right)$ (Sokolichin et al., 2004): 
$132 \frac{3}{4} \frac{C_{\mathrm{d}}}{d_{\mathrm{b}}}\left|U_{\text {slip }}\right| U_{\text {slip }}=-\nabla p$

$133 \quad C_{\mathrm{d}}=\frac{0.622}{\frac{1}{\mathrm{E} \ddot{0}}+0.235}$

$134 \quad$ Ë̈ $=\frac{\mathrm{g} \rho_{l} d_{\mathrm{b}}{ }^{2}}{\sigma}$

135 where $C_{\mathrm{d}}$ denotes the drag coefficient $(1), d_{\mathrm{b}}$ represents the gas bubble diameter $(0.008 \mathrm{~m}$ in this

136 study measured through experiments), and $\sigma$ refers to the surface tension coefficient $(0.07 \mathrm{~N} / \mathrm{m}$,

137 commonly used in the water-air system (Pallas and Harrison, 1990)).

138 The $k-\varepsilon$ turbulence model was used to model the turbulence generated in the PBR. The turbulent 139 kinetic energy $\left(k_{t}\right)$ and the dissipation rate $(\varepsilon)$ equations are as follows:

$140 \quad \frac{\partial}{\partial t}\left(\rho_{l} k_{t}\right)+\rho_{l} U_{l} \cdot \nabla k_{t}$

141

$$
=\nabla \cdot\left[\left(\mu_{l}+\frac{\mu_{T}}{\sigma_{k}}\right) \nabla k_{t}\right]+\frac{1}{2} \mu_{T}\left(\nabla U_{l}+\left(\nabla U_{l}\right)^{T}\right)^{2}-\rho_{l} \varepsilon-C_{k} \varphi_{g} \nabla p \cdot U_{\text {slip }}
$$

$142 \frac{\partial}{\partial t}\left(\rho_{l} \varepsilon\right)+\rho_{l} U_{l} \cdot \nabla \varepsilon$

143

$$
=\nabla \cdot\left[\left(\mu_{l}+\frac{\mu_{T}}{\sigma_{\varepsilon}}\right) \nabla \varepsilon\right]+\frac{1}{2} C_{\varepsilon 1} \frac{\varepsilon}{k} \mu_{T}\left(\nabla U_{l}+\left(\nabla U_{l}\right)^{T}\right)^{2}-\rho_{l} C_{\varepsilon 2} \frac{\varepsilon^{2}}{k}-\frac{\varepsilon}{k} C_{\varepsilon} C_{k} \varphi_{g} \nabla p
$$

$145 \quad \mu_{T}=\frac{\rho_{l} C_{\mu} k_{t}^{2}}{\varepsilon}$

146 where $\mu_{T}$ represents the dynamic viscosity $(\mathrm{Pa} \cdot \mathrm{s}), C_{k}(0.505)$ refers to the bubble-induced 147 turbulence parameter, $\sigma_{k}(1)$ and $\sigma_{\varepsilon}(1.3)$ represent the turbulent Prandtl numbers, and $C_{\varepsilon 1}(1.44)$ 
148 and $C_{\varepsilon 2}$ (1.92) denote the first and second experimental model constants, respectively. The $k-\varepsilon$ 149 turbulence model uses the experimentally derived values of these model constants (Wilcox, 150 2006).

151 Friction velocity is a classical form to represent shear stress in units of velocity, and it helps to 152 estimate the shear rate in a flow. Therefore, friction velocity was used to evaluate the shear 153 stresses imposed on the microalgae in the PBR. The friction velocity can be expressed as follows 154 (Leupold et al., 2013; Michels et al., 2016):

$155 U_{f}=\left(\frac{\tau_{s}}{\rho_{l}}\right)^{1 / 2}$

156 where $U_{f}$ is the friction velocity $(\mathrm{cm} / \mathrm{s})$, and $\tau_{s}$ is the shear stress $(\mathrm{Pa})$. A friction velocity higher 157 than $1 \mathrm{~cm} / \mathrm{s}$ damages $C$. reinhardtii cells and decreases their photosynthetic efficiencies (Leupold 158 et al., 2013; Michels et al., 2016). The decrease in the photosynthetic efficiency caused by high 159 friction velocity $(>1 \mathrm{~cm} / \mathrm{s})$ reduces the PBR productivity. The loss in PBR productivity was 160 estimated by calculating the productive and unproductive volumes of the reactor. The productive 161 volume is the PBR region that produces biofuel and exhibits a local friction velocity of less than $1621 \mathrm{~cm} / \mathrm{s}$. The unproductive or dead zone volume can be defined as the region with no biofuel 163 production but with local friction velocity higher than $1 \mathrm{~cm} / \mathrm{s}$. Apart from that dead zone can also 164 mean the region where culture mixing is too slow to maintain an effective biomass movement. 165 Thus, cells are stagnant and not able to receive nutrients promptly. However, it was confirmed by 166 previously published experimental results that culture mixing is maintaining an effective biomass 167 movement in the photobioreactor (Harun et al., 2018; del Rio-Chanona et al., 2019; Zhang et al., 168 2015a; Zhang et al., 2015c; Zhang et al., 2015b). These results imply that dead zones due to low 169 culture mixing were not observed in the experiments. Thus, all the parameters used in the present 
170 study were derived from previous experimental data to ensure effective biomass movement. For

171 this reason, it was assumed that the dead zones due to low culture mixing are negligible and thus

172 were not discussed in the present study. The loss in PBR productivity was calculated using the

173 following equation:

174 Productivity loss $(\%)=\frac{\text { Unproductive or dead zone volume }(\mathrm{L})}{P B R \text { total volume }(L)} \times 100$

\section{2.2. Microalgal growth and bisabolene production modelling}

176 In our recent study, a kinetic model was proposed to simulate microalgae biomass growth and

177 bisabolene production from a genetically modified $C$. reinhardtii strain (Harun et al., 2018; del

178 Rio-Chanona et al., 2019). The study used the logistic model (Dechatiwongse et al., 2014; del

179 Rio-Chanona et al., 2017; del Rio-Chanona et al., 2019) to simulate the biomass growth rate in 180 the PBR with the assumption that nutrients are supplied in excess. The logistic model defines the 181 biomass growth rate as follows:

$182 \frac{d X}{d t}=\mu \cdot X-\mu_{d} \cdot X^{2}+\nabla \cdot\left(U_{l} \cdot X\right)$

183 where $X$ is the biomass concentration (g/L), $\mu$ is the biomass specific growth rate $(1 / \mathrm{h})$, and $\mu_{d}$ is 184 the biomass specific decay rate $(\mathrm{L} / \mathrm{g} / \mathrm{h})$. The biomass specific growth rate $(\mu)$ depends on the 185 light intensity and culture temperature. The Aiba and Arrhenius models (Zhang et al., 2015a) 186 were used to simulate the influences of light intensity and temperature on biomass growth, 187 respectively. The governing equations of biomass specific growth rate $(\mu)$, light intensity $(I)$, and 188 culture temperature $(T)$ can be written as follows:

$189 \mu=\mu_{m} \cdot k(I) \cdot k(T)$ 
$190 \quad k(I)=\frac{I(t, z)}{I(t, z)+k_{s}+\frac{I^{2}(t, z)}{k_{i}}}$

$191 \quad k(T)=\exp \left[-\left(\frac{E_{a}}{R T}-\frac{E_{a}}{R T_{a}}\right)\right]-\exp \left[-\left(\frac{E_{b}}{R T}-\frac{E_{b}}{R T_{b}}\right)\right]$

192 where $\mu_{m}$ represents the maximum biomass specific growth rate $(0.3041 / \mathrm{h}), I(z)$ refers to the 193 local light intensity $\left(\mu \mathrm{E} / \mathrm{m}^{2} / \mathrm{s}\right), k_{s}$ denotes the photosaturation term $\left(34.92 \mu \mathrm{E} / \mathrm{m}^{2} / \mathrm{s}\right), k_{i}$ represents 194 the photoinhibition term $\left(441.2 \mu \mathrm{E} / \mathrm{m}^{2} / \mathrm{s}\right), E_{a}$ refers to the algal activation energy $(144 \mathrm{~kJ} / \mathrm{mol})$, $195 E_{b}$ denotes the algal deactivation energy $(343.9 \mathrm{~kJ} / \mathrm{mol})$, and $T_{a}(306.7 \mathrm{~K})$ and $T_{b}(307.1 \mathrm{~K}) \mathrm{refer}$ 196 to the reference temperatures. All the parameter values were obtained from the recent study 197 (Harun et al., 2018; del Rio-Chanona et al., 2019).

198 Light distribution within photobioreactor can be influenced by scattering, reflection, and refraction 199 of light caused by the algae cells, liquid medium, gas bubbles, and reactor geometry. Nevertheless, 200 it is not possible to include the effects of these parameters into a single model. Lambert-Beer law is 201 one of the existing models that comprehensively consists of the light scattering and absorption 202 effects by gas bubbles and algae cells. Light attenuation remains dependent on light penetration 203 distance, which suggests that the local light intensity $(I(t, z))$ is affected by cell absorption and 204 bubble scattering (Zhang et al., 2015b). Therefore, the local light intensity experienced by 205 microalgal cells in the culture is much lower than the incident light intensity. The modified 206 Lambert-Beer's law was used to model the local light intensity by taking into account the 207 microalgal cell absorption and bubble scattering (Béchet et al., 2013b; Zhang et al., 2015b). The 208 governing equation of the local light intensity $(I(t, z))$ includes both spatial (light transmission 209 direction) and time dimensions and is given as follows:

210

$I(t, z)=I_{0}(t, z) \cdot \exp \left[-\left(\tau \cdot X(t, z)+K_{a}\right) \cdot z\right]$ 
211 where $I_{0}$ is the incident light intensity $\left(60 \mu \mathrm{E} / \mathrm{m}^{2} / \mathrm{s}\right), \tau$ is the algal cell absorption coefficient

$212\left(33.9 \mathrm{~m}^{2} / \mathrm{g}\right), K_{a}$ is the bubble scattering coefficient $(1 / \mathrm{m})$, and $z$ is the distance from the light

213 source $(\mathrm{m}) . K_{a}$ is defined using the following equation (Zhang et al., 2015b):

$214 \quad K_{a}=\frac{3 \varphi_{g}}{d_{\mathrm{b}}}$

215 The bubble volume fraction was calculated using the CFD model and then imported to the 216 kinetic model for evaluating light intensity. Bisabolene production in the PBR was simulated 217 using the modified Luedeking-Piret model (Mu et al., 2015). The governing equation of the 218 bisabolene production is shown as follows:

$219 \quad \frac{d P}{d t}=\left(Y_{1} \cdot \frac{d X}{d t}+Y_{2} \cdot X\right) \cdot(\alpha-k(T))$

220 where $P$ is the bisabolene production $(\mu \mathrm{g} / \mathrm{L}), Y_{1}$ is the biomass growth-associated bisabolene 221 yield coefficient $(326.7 \mu \mathrm{g} / \mathrm{g}), Y_{2}$ is the biomass growth-independent bisabolene yield coefficient $222(1.758 \mu \mathrm{g} / \mathrm{g} / \mathrm{h})$, and $\alpha$ is the temperature-dependent bisabolene synthesis rate $(0.474)$. The values 223 of the parameters used in mathematical modelling were derived from previous experimental data 224 (Harun et al., 2018). A detailed introduction of the kinetic model can be found in our previous 225 work (del Rio-Chanona et al., 2019).

226 COMSOL Multiphysics (5.3a, COMSOL Inc., Burlington, MA, USA) was used to estimate the 227 gas-liquid flow mixing, microalgal growth, and bisabolene production in the pilot-scale PBR. 228 The computational fluid dynamics (CFD model) was simulated using the turbulent bubbly flow 229 interface of COMSOL Multiphysics. Then, the liquid velocity from the CFD model is imported 230 to the biochemical reaction kinetics (kinetic model), and these are simulated using the partial 231 differential equation (PDE) interfaces of COMSOL Multiphysics. A transient solver was used to 232 solve the turbulent bubbly flow and the PDE interfaces of COMSOL Multiphysics for $40 \mathrm{~h}$. The 
233 time-dependent approach helps the hybrid model to compute and compare biomass growth and

234 bisabolene production with previous experimental data (Harun et al., 2018) at different time

235 intervals. This approach makes it more realistic than the steady-state simulation. Moreover, the

236 computational time in this particular study largely depends on grid size and less on simulation

237 type (transient or steady-state), keeping in view the large volume of the photobioreactor (120 L).

238 The results of grid independency test, light intensity, and power input are presented in Appendix-

239 A. For complex systems such as photobioreactors, averaging the spatial distribution of the

240 parameters (bubble volume fraction, light intensity, friction velocity, power input, biomass

241 concentration, and bisabolene production) is a reasonable approach to effectively present the

242 results for better understanding (Fernández et al., 2014; de Mooij et al., 2016).

\section{3. Experimental validation}

244 The proposed CFD and kinetic-based model was initially compared and validated using 245 previously published experimental data obtained from a 1 L lab-scale PBR (Harun et al., 2018; 246 del Rio-Chanona et al., 2019; Zhang et al., 2015b; Zhang et al., 2015a). The biomass 247 concentration and bisabolene production were simulated in a $1 \mathrm{~L}$ PBR with a $W$ of $200 \mathrm{~mm}, H$ of $248140 \mathrm{~mm}$, and $D$ of $25 \mathrm{~mm}$. The sparger (diameter $=5 \mathrm{~mm}$ and $W=200 \mathrm{~mm}$ ) with 20 holes 249 (diameter of holes $=1 \mathrm{~mm}$ ) was used to provide recycling gas at a velocity of $0.47 \mathrm{~m} / \mathrm{s}$ from the 250 bottom of the PBR. The lab-scale PBR was discretized with; a tetrahedral grid type and grid size 251 of 94,850 domains, 8,266 boundaries, and 380 edge elements. The proposed CFD and kinetic252 based model in this study (described in section 2) was used to estimate gas-liquid flow mixing, 253 microalgal growth, and bisabolene production in the lab-scale PBR. The values of all parameters 254 used in the simulations were obtained from the experimental results (Harun et al., 2018; Zhang et 255 al., 2015a). The average bubble volume fraction of the present study was 0.00614 , which is close 
256 to that of the experimentally calculated bubble volume fraction (0.0067) (Zhang et al., 2015a).

257 The maximum difference between the modelling (present study) and experimental (Harun et al., 258 2018; Zhang et al., 2015b) results of biomass concentration was $3.94 \%$ at the $65^{\text {th }} \mathrm{h}$, and that of 259 the bisabolene production is $10.99 \%$ at the $73^{\text {rd }} \mathrm{h}$ (Figures $2(\mathrm{a})$ and $2(\mathrm{~b})$ ). The present results are 260 in reasonable agreement with the experimental results, thereby verifying the accuracy of the 261 developed CFD and kinetic-based model.

\section{4. Results and discussion}

263 4.1. Bubble volume fraction

264 Local light intensity depends on gas bubble scattering, and its uniform distribution in the PBR is 265 essential for microalgal growth. However, a significant difference in bubble volume fraction 266 changes the uniformity of local light intensity (Zhang et al., 2015b). Varying the number and 267 diameter of sparger holes remarkably affects the bubble volume fraction (Figure 3(a)). An increase 268 in the number of sparger holes decreases the bubble volume fraction in the PBR. Increasing the 269 diameter of holes results in a manner similar to that when increasing the number of holes. 270 Increasing the recycling gas flow rate also increases the bubble volume fraction, which 271 consequently enhances the culture mixing in the PBR. This increased mixing rate helps in the 272 transfer of nutrients to microalgal cells. Nevertheless, a substantial increase in the bubble volume 273 fraction can reduce the distribution of local light intensity in the PBR. Therefore, a balance must be 274 maintained in the selection of the number and diameter of sparger holes to ensure that bubble 275 volume fraction may not significantly affect the local light intensity. Therefore, the number and 276 diameter of holes and gas flow rate in the range of 92-104, 1.0-2.5 $\mathrm{mm}$, and $14.5-17.5 \mathrm{~L} / \mathrm{min}$, 277 respectively, are suitable in generating bubble volume fraction of 0.0055 in the current pilot-scale 278 PBR. 
Developing an empirical correlation can be helpful in selecting the optimal bubble volume

281 fraction to reduce the effects of bubble scattering on the local light intensity and generate 282 effective mixing in the PBR. Integrating the empirical correlation for bubble volume fraction 283 with Lambert-Beer's law (Equation 19 and Equation 20) enables the modelling of the light 284 transmission in the PBR. The number of parameters on which the bubble volume fraction in the 285120 L PBR may depend on was determined via dimensional analysis. The bubble volume 286 fraction depends on the number of sparger holes $\left(N_{H}\right)$, sparger hole diameter $\left(D_{H}\right)$, sparger hole 287 pitch $\left(P_{H}\right)$, sparger diameter $\left(D_{S}\right)$, bubble diameter $\left(d_{\mathrm{b}}\right)$, and Reynolds number $(R e)$. The 288 empirical correlation for the bubble volume fraction $\left(\varphi_{g}\right)$ in pilot-scale PBR was obtained using 289 Buckingham's $\pi$ theorem, and it can be written as follows based on the present simulation data 290 (shown in Figure 4):

291

$\varphi_{g}=C_{o}\left(\frac{1}{N_{H}}\right)^{a}\left(\frac{d_{\mathrm{b}}}{D_{H}}\right)^{b}\left(\frac{P_{H}}{D_{S}}\right)^{c}(\mathrm{Re})^{d}$

$292 R e=\frac{U_{g} D_{\mathrm{h}}}{v}$

$293 \quad D_{\mathrm{h}}=\frac{4 W D}{2(W+D)}$

294 where $v$ is the kinematic viscosity of liquid, $U_{g}$ is the gas velocity, and $D_{\mathrm{h}}$ is the hydraulic 295 diameter of the PBR (m) (Ratchford and Fallowfield, 1992). Additionally, $C_{o}$ is the constant, and $296 a, b$, and $c$ are the exponents to be calculated using nonlinear regression analysis. The empirical 297 correlation for the bubble volume fraction can be written in the following form after calculation 298 of the pending coefficients:

$299 \varphi_{g}=0.0018\left(\frac{1}{N_{H}}\right)^{-0.0164}\left(\frac{d_{\mathrm{b}}}{D_{H}}\right)^{0.0326}\left(\frac{P_{H}}{D_{S}}\right)^{0.2587}(R e)^{0.0065}, \quad R^{2}=0.99$ 
300 The empirical correlation (Equation 25) used to calculate the bubble volume fraction was valid

301 for $62 \leq N_{H} \leq 122,1 \leq D_{H} \leq 5 \mathrm{~mm}, 13 \leq P_{H} \leq 26 \mathrm{~mm}$, and $3.5 \times 10^{4} \leq R e \leq 1.4 \times 10^{5}$. Results were

302 plotted with the CFD data (Figure 4). A close agreement is observed between the results of the

303 bubble volume fraction calculated using the empirical correlation and the CFD data. The

304 standard error is approximately $0.77 \%$. These results confirmed that the proposed empirical

305 correlation (Equation 25) can be used to compute the bubble volume fraction in large-scale PBR

306 effectively and consequently determine the local light intensity.

\section{4.3. Friction velocity}

308 A detailed investigation on the effects of friction velocity (shear stress) on algal cells is 309 necessary for the design and scale-up of PBRs. PBR sparger exerts a major influence on the 310 friction velocity because of its direct relationship with mixing (Figure 5). Increasing the number 311 and diameter of sparger holes reduces the effects of friction velocity on algae cells. By contrast, 312 the friction velocity increases when the sparger operates at high gas flow rates. High gas 313 sparging rates produce a large number of bubbles that improve culture mixing by prompting the 314 liquid circulation in the PBR. Bursting of these large number of bubbles increases the friction 315 velocity and consequently reduces the photosynthetic efficiency of algae cells. However, the 316 friction velocities presented in the Figure 5 are their average values. These results imply that 317 despite the value of average friction velocity less than $1 \mathrm{~cm} / \mathrm{s}$ (Figure 5), there could be regions 318 in the PBR with the local friction velocity higher than $1 \mathrm{~cm} / \mathrm{s}$. Thus, it is essential to quantify the 319 local friction velocity and productive volume of the PBR. The productive and unproductive or 320 dead zone volumes resulting from the different sparger designs were also estimated (Table 2).

321 The productive volume of the PBR is at maximum (productivity loss of only $1.66 \%$ ) when the 322 recycling gas is provided using sparger design 3 (number of holes $=122$, hole diameter $=1 \mathrm{~mm}$, 
323 and recycling gas flow rate $=5 \mathrm{~L} / \mathrm{min}$ ). The sparger design 3 results in better productive volume

324 than the other sparger designs because of the minimum dead zones produced by a large number

325 of holes and low gas flow rate. The maximum productivity loss is observed at sparger designs 2

326 (number of holes $=62$, hole diameter $=1 \mathrm{~mm}$, and recycling gas flow rate $=20 \mathrm{~L} / \mathrm{min}$ ) and 6

327 (number of holes $=62$, hole diameter $=5 \mathrm{~mm}$, and recycling gas flow rate $=20 \mathrm{~L} / \mathrm{min}$ ), thereby

328 indicating their unsuitability in biofuel production. This study effectively assumed and estimated

329 the unproductive regions in the PBR. However, in actual conditions, the mixing forces the algal

330 cells to move through the entire reactor. Thus, the damaged cells from the unproductive regions

331 would still be unproductive in the rest of the system that eventually causes the death of the whole

332 culture, unless growth exceeds this. These results suggested that the number and diameter of

333 holes and gas flow rate in the range of 115-122, 4.5-5.0 mm, and 5.0-7.5 L/min, respectively, are

334 potentially suitable with optimized friction velocity $(0.66 \mathrm{~m} / \mathrm{s})$.

\subsection{Biomass concentration and bisabolene production}

336 Finally, the effects of the sparger design parameters (number and diameter of sparger holes and 337 gas flow rate) on average biomass concentration and bisabolene production were estimated and 338 analyzed. The biomass concentration decreases with an increase in the number and diameter of 339 sparger holes (Figure 6). This decrease in biomass concentration indicates the low liquid 340 circulation in the PBR due to the use of a large number and diameter of sparger holes. Increasing 341 the gas flow rates improves the liquid circulation in the PBR, which consequently increases the 342 biomass concentration. Increasing the number and diameter of sparger holes and gas flow rates 343 affects the bisabolene production in manner similar to that on the biomass concentration. Although, 344 using the minimum hole number and diameter and maximum gas flow rate significantly 345 improves the mixing which in turn increases the biomass concentration and bisabolene 
346 production. The local friction velocity is higher than $1 \mathrm{~cm} / \mathrm{s}$ for these sparger design parameters. In

347 actual conditions, the biomass concentration and bisabolene production must decrease using the

348 minimum hole number and diameter and maximum gas flow rate because the friction velocity

349 exceeds $1 \mathrm{~cm} / \mathrm{s}$. However, the proposed model has a limitation that it cannot automatically reduce

350 the biomass concentration and bisabolene production when the frictional velocity reaches beyond

351 the critical value $(1 \mathrm{~cm} / \mathrm{s})$. Thus, to optimize the biomass concentration $(0.6 \mathrm{~g} / \mathrm{L})$ and bisabolene

352 production $(25.05 \mu \mathrm{g} / \mathrm{L})$ in the current pilot-scale PBR and meanwhile to consider the impact of

353 hydrodynamics on cell damage, the number and diameter of holes and gas flow rates should be

354 fixed in the range of $115-122,4.5-5.0 \mathrm{~mm}$, and 5.0-7.5 L/min (Figure 6), respectively.

\section{5. Conclusion}

356 This study implemented a CFD and algal growth kinetic-based model to optimize the sparger 357 design for a $120 \mathrm{~L}$ pilot-scale PBR. The effects of different sparger designs on biomass growth 358 and biofuel production were examined. The optimized sparger design parameters (number and 359 diameter of holes and gas flow rate) were selected based on their effects on bubble volume 360 fraction, average light intensity, friction velocity, power input, biomass concentration, and 361 bisabolene production. The PBR productivity loss due to cell damage (dead zones) was 362 calculated. A new empirical correlation was proposed to estimate the bubble volume fraction in 363 large-scale PBRs.

364 The present study found that the sparger design significantly affected biofuel production in the 365 pilot-scale PBR. The number and diameter of sparger holes were inversely related to the bubble 366 volume fraction, friction velocity, biomass concentration, and bisabolene production, but gas 367 flow rate was directly related to them. Providing recycling gas to the PBR under high flow rates 368 improved culture mixing, however, it also required substantial power. The increase in bubble 
369 volume fraction significantly increased the culture mixing, but it also disturbed local light

370 intensity and induced shear stresses on algal cells. The proposed empirical correlation effectively

371 estimated the bubble volume fraction, and it can be helpful in determining the local light

372 intensity in the PBR by integrating the light transmission equations (Equation 19 and Equation

373 20). The increased liquid circulation due to high gas flow rate also increased the shear-induced

374 cell damage (dead zones), as shown by the substantial productivity losses of the PBR. To scale up 375 the biofuel production process, this study recommends the optimized number and diameter of 376 sparger holes and gas flow rate to be in the range of $115-122,4.5-5.0 \mathrm{~mm}$, and $5.0-7.5 \mathrm{~L} / \mathrm{min}$, 377 respectively. It may be possible in future, that a shear stress-related condition could be included in 378 the proposed hybrid model that permits it to automatically decrease the biofuel production when 379 the friction velocity exceeds $1 \mathrm{~cm} / \mathrm{s}$. Furthermore, keeping in view the scaling-up of PBRs, it is 380 encouraged to develop an empirical model for biofuel production correlating different parameters 381 (bubble scattering, reactor geometry, light intensity, temperature, growth rates, etc.).

\section{Acknowledgements}

383 This study was supported by a National Research Foundation of Korea (NRF) grant funded by 384 the Korea government (MSIP) (No. 2017R1A2B2005515), and a grant from the Priority 385 Research Centers Program through the NRF, as funded by the MEST (No. 2010-0020089).

\section{Declaration of interest: none}

\section{$387 \quad$ References}

Barbosa MJ, Hadiyanto, Wijffels RH. 2004. Overcoming Shear Stress of Microalgae Cultures in Sparged Photobioreactors. Biotechnol. Bioeng. 85:78-85.

Béchet Q, Muñoz R, Shilton A, Guieysse B. 2013a. Outdoor cultivation of temperature-tolerant 
Chlorella sorokiniana in a column photobioreactor under low power-input. Biotechnol. Bioeng. 110:118-126.

Béchet Q, Shilton A, Guieysse B. 2013b. Modeling the effects of light and temperature on algae growth: State of the art and critical assessment for productivity prediction during outdoor cultivation. Biotechnol. Adv. 31:1648-1663.

Becker S, Sokolichin a., Eigenberger G. 1994. Gas-liquid flow in bubble columns and loop reactors: Part II. Comparison of detailed experiments and flow simulations. Chem. Eng. Sci. 49:5747-5762.

Berberoglu H, Yin J, Pilon L. 2007. Light transfer in bubble sparged photobioreactors for H2production and CO2mitigation. Int. J. Hydrogen Energy 32:2273-2285.

Bergmann P, Trösch W. 2016. Repeated fed-batch cultivation of Thermosynechococcus elongatus BP-1 in flat-panel airlift photobioreactors with static mixers for improved light utilization: Influence of nitrate, carbon supply and photobioreactor design. Algal Res. 17:79-86.

Carvalho AP, Meireles LA, Malcata FX. 2006. Microalgal Reactors: A Review of Enclosed System Designs and Performances. Biotechnol. Prog. 22:1490-1506.

Chen Z, Jiang Z, Zhang X, Zhang J. 2016. Numerical and experimental study on the CO2 gasliquid mass transfer in flat-plate airlift photobioreactor with different baffles. Biochem. Eng. J. 106:129-138.

Chisti Y. 1998. Pneumatically Agitated Bioreactors in Industrial and Environmental Bioprocessing: Hydrodynamics, Hydraulics, and Transport Phenomena. Appl. Mech. Rev. 51:33.

Chisti Y. 2007. Biodiesel from microalgae. Biotechnol. Adv. 25:294-306.

Dechatiwongse P, Srisamai S, Maitland G, Hellgardt K. 2014. Effects of light and temperature on the photoautotrophic growth and photoinhibition of nitrogen-fixing cyanobacterium Cyanothece sp. ATCC 51142. Algal Res. 5:103-111.

Fernandes BD, Dragone GM, Teixeira JA, Vicente AA. 2010. Light regime characterization in an airlift photobioreactor for production of microalgae with high starch content. Appl. 
Biochem. Biotechnol. 161:218-226.

420

421

422

423

424

425

426

427

428

429

430

431

432

433

434

435

436

437

438

439

440

441

442

443

444

445

Fernández I, Acién FG, Berenguel M, Guzmán JL. 2014. First Principles Model of a Tubular Photobioreactor for Microalgal Production. Ind. Eng. Chem. Res. 53:11121-11136.

Gupta PL, Lee S-M, Choi H-J. 2015. A mini review: photobioreactors for large scale algal cultivation. World J. Microbiol. Biotechnol. 31:1409-1417.

Harun I, Del Rio-Chanona EA, Wagner JL, Lauersen KJ, Zhang D, Hellgardt K. 2018. Photocatalytic Production of Bisabolene from Green Microalgae Mutant: Process Analysis and Kinetic Modeling. Ind. Eng. Chem. Res. 57:10336-10344.

Huang J, Feng F, Wan M, Ying J, Li Y, Qu X, Pan R, Shen G, Li W. 2015. Improving performance of flat-plate photobioreactors by installation of novel internal mixers optimized with computational fluid dynamics. Bioresour. Technol. 182:151-159.

Huang J, Li Y, Wan M, Yan Y, Feng F, Qu X, Wang J, Shen G, Li W, Fan J, Wang W. 2014. Novel flat-plate photobioreactors for microalgae cultivation with special mixers to promote mixing along the light gradient. Bioresour. Technol. 159:8-16.

Kulkarni A V., Roy SS, Joshi JB. 2007. Pressure and flow distribution in pipe and ring spargers: Experimental measurements and CFD simulation. Chem. Eng. J. 133:173-186.

Lestinsky P, Vayrynen P, Vecer M, Wichterle K. 2012. Hydrodynamics of Airlift Reactor with Internal Circulation Loop: Experiment vs. CFD Simulation. Procedia Eng. 42:892-907.

Leupold M, Hindersin S, Gust G, Kerner M, Hanelt D. 2013. Influence of mixing and shear stress on Chlorella vulgaris, Scenedesmus obliquus, and Chlamydomonas reinhardtii. J. Appl. Phycol. 25:485-495.

Luo HP, Al-Dahhan MH. 2004. Analyzing and Modeling of Photobioreactors by Combining First Principles of Physiology and Hydrodynamics. Biotechnol. Bioeng. 85:382-393.

Luo L, Liu F, Xu Y, Yuan J. 2011. Hydrodynamics and mass transfer characteristics in an internal loop airlift reactor with different spargers. Chem. Eng. J. 175:494-504.

Michels MHA, van der Goot AJ, Vermuë MH, Wijffels RH. 2016. Cultivation of shear stress sensitive and tolerant microalgal species in a tubular photobioreactor equipped with a 
centrifugal pump. J. Appl. Phycol. 28:53-62.

447

448

449

450

451

452

453

454

455

456

457

458

459

460

461

462

463

464

465

466

467

468

469

470

471

472

Molina Grima E, Garcia Carnacho F, Sanchez Perez J a, Fernandez Sevilla JM, Acien Fernandez FG, Contreras Gomez a. 1994. in Light-Limited Chemostat Culture. J. Chem. Technol. Biotechnol. 61:167-173.

de Mooij T, de Vries G, Latsos C, Wijffels RH, Janssen M. 2016. Impact of light color on photobioreactor productivity. Algal Res. 15:32-42.

Mu Y, Yang H-Y, Wang Y-Z, He C-S, Zhao Q-B, Wang Y, Yu H-Q. 2015. The maximum specific hydrogen-producing activity of anaerobic mixed cultures: definition and determination. Sci. Rep. 4:5239.

Pallas NR, Harrison Y. 1990. An automated drop shape apparatus and the surface tension of pure water. Colloids and Surfaces 43:169-194.

Posten C. 2009. Design principles of photo-bioreactors for cultivation of microalgae. Eng. Life Sci. 9:165-177.

Ranade V V., Tayalia Y. 2001. Modelling of fluid dynamics and mixing in shallow bubble column reactors: Influence of sparger design. Chem. Eng. Sci. 56:1667-1675.

Ratchford IAJ, Fallowfield HJ. 1992. Performance of a flat plate, air-lift reactor for the growth of high biomass algal cultures. J. Appl. Phycol. 4:1-9.

del Rio-Chanona EA, Ling X, Zhang D, Tang Y, Jing K, Yao C. 2017. Overproduction of Ltryptophan via simultaneous feed of glucose and anthranilic acid from recombinant Escherichia coli W3110: Kinetic modeling and process scale-up. Biotechnol. Bioeng. 115:371-381.

del Rio-Chanona EA, Wagner JL, Ali H, Fiorelli F, Zhang D, Hellgardt K. 2019. Deep learningbased surrogate modeling and optimization for microalgal biofuel production and photobioreactor design. AIChE J. 65:915-923.

Sforza E, Simionato D, Giacometti GM, Bertucco A, Morosinotto T. 2012. Adjusted light and dark cycles can optimize photosynthetic efficiency in algae growing in photobioreactors. PLoS One 7:e38975. 
Singh RN, Sharma S. 2012. Development of suitable photobioreactor for algae production - A review. Renew. Sustain. Energy Rev. 16:2347-2353.

Sokolichin a., Eigenberger G, Lapin a. 2004. Simulation of Buoyancy Driven Bubbly Flow: Established Simplifications and Open Questions. AIChE J. 50:24-45.

Su Z, Kang R, Shi S, Cong W, Cai Z. 2010. Study on the destabilization mixing in the flat plate photobioreactor by means of CFD. Biomass and Bioenergy 34:1879-1884.

Sun Y, Huang Y, Liao Q, Fu Q, Zhu X. 2016. Enhancement of microalgae production by embedding hollow light guides to a flat-plate photobioreactor. Bioresour. Technol. 207:3138.

Thomas WH, Gibson CH. 1990. Effects of small-scale turbulence on microalgae. J. Appl. Phycol. 2:71-77.

Wichmann J, Baier T, Wentnagel E, Lauersen KJ, Kruse O. 2018. Tailored carbon partitioning for phototrophic production of (E)- $\alpha$-bisabolene from the green microalga Chlamydomonas reinhardtii. Metab. Eng. 45:211-222.

Wilcox DC. 2006. Turbulence Modeling for CFD. Flintridge, CA, USA: DCW Industries. Turbulence Modeling for CFD.

Yang Z, Cheng J, Xu X, Zhou J, Cen K. 2016. Enhanced solution velocity between dark and light areas with horizontal tubes and triangular prism baffles to improve microalgal growth in a flat-panel photo-bioreactor. Bioresour. Technol. 211:519-526.

Zhang D, Dechatiwongse P, del Rio-Chanona EA, Maitland GC, Hellgardt K, Vassiliadis VS. 2015a. Modelling of light and temperature influences on cyanobacterial growth and biohydrogen production. Algal Res. 9:263-274.

Zhang D, Dechatiwongse P, Hellgardt K. 2015b. Modelling light transmission, cyanobacterial growth kinetics and fluid dynamics in a laboratory scale multiphase photo-bioreactor for biological hydrogen production. Algal Res. 8:99-107.

Zhang D, Dechatiwongse P, del Rio-Chanona EA, Maitland GC, Hellgardt K, Vassiliadis VS. 2015c. Dynamic modelling of high biomass density cultivation and biohydrogen production in different scales of flat plate photobioreactors. Biotechnol. Bioeng. 112:2429-2438. 
501 Zhang K, Kurano N, Miyachi S. 2002. Optimized aeration by carbon dioxide gas for microalgal 502 production and mass transfer characterization in a vertical flat-plate photobioreactor. 503 Bioprocess Biosyst. Eng. 25:97-101.

504 Nomenclature

$505 \quad$ cross-sectional area of PBR $\left(\mathrm{m}^{2}\right)$

$506 \quad C_{\mathrm{d}} \quad$ drag coefficient (1)

$507 \quad d_{\mathrm{b}} \quad$ gas bubble diameter $(\mathrm{m})$

$508 D_{H} \quad$ sparger hole diameter $(\mathrm{mm})$

$509 \quad D_{S} \quad$ sparger diameter $(\mathrm{mm})$

$510 \quad E_{a} \quad$ algae activation energy $(\mathrm{kJ} / \mathrm{mol})$

$511 E_{b} \quad$ algae deactivation energy $(\mathrm{kJ} / \mathrm{mol})$

$512 \mathrm{~g}$ gravity vector $\left(\mathrm{m} / \mathrm{s}^{2}\right)$

$513 \quad h_{l} \quad$ unaerated liquid height (m)

$514 \quad I_{0} \quad$ incident light intensity $\left(\mu \mathrm{E} / \mathrm{m}^{2} / \mathrm{s}\right)$

$515 \quad I(z) \quad$ local light intensity $\left(\mu \mathrm{E} / \mathrm{m}^{2} / \mathrm{s}\right)$

$516 k_{i} \quad$ photoinhibition term $\left(\mu \mathrm{E} / \mathrm{m}^{2} / \mathrm{s}\right)$

$517 \quad k_{s} \quad$ photosaturation term $\left(\mu \mathrm{E} / \mathrm{m}^{2} / \mathrm{s}\right)$

$518 K_{a} \quad$ bubble scattering coefficient $(1 / \mathrm{m})$

$519 \mathrm{~m}_{g l} \quad$ mass transfer rate $\left(\mathrm{kg} / \mathrm{m}^{3} \cdot \mathrm{s}\right)$

$520 \quad N_{H} \quad$ number of sparger holes

$521 p \quad$ pressure $(\mathrm{Pa})$

$522 P \quad$ bisabolene production $(\mu \mathrm{g} / \mathrm{L})$

$523 P_{h} \quad$ pressure at the top of sparger holes $(\mathrm{Pa})$

$524 \quad P_{H} \quad$ sparger hole pitch $(\mathrm{mm})$

$525 P_{S} \quad$ power input $\left(\mathrm{W} / \mathrm{m}^{3}\right)$

$526 Q \quad$ gas volumetric flow rate $(\mathrm{L} / \mathrm{min})$

$527 \quad Q_{\mathrm{m}} \quad$ gas molar flow rate $(\mathrm{mol} / \mathrm{s})$ 


\begin{tabular}{|c|c|c|}
\hline 528 & $R$ & gas constant $(\mathrm{J} / \mathrm{mol} \cdot \mathrm{K})$ \\
\hline 529 & $R e$ & Reynolds number (1) \\
\hline 530 & $T$ & temperature $(\mathrm{K})$ \\
\hline 531 & $U$ & velocity vector $(\mathrm{m} / \mathrm{s})$ \\
\hline 532 & $U_{g}$ & gas velocity $(\mathrm{m} / \mathrm{s})$ \\
\hline 533 & $U_{f}$ & friction velocity $(\mathrm{cm} / \mathrm{s})$ \\
\hline 534 & $U_{s}$ & superficial gas velocity $(\mathrm{m} / \mathrm{s})$ \\
\hline 535 & $X$ & biomass concentration (g/L) \\
\hline 536 & $Z$ & distance from light source $(\mathrm{m})$ \\
\hline 537 & Greek symb & \\
\hline 538 & $\alpha$ & bisabolene synthesis rate (1) \\
\hline 539 & $\rho$ & density $\left(\mathrm{kg} / \mathrm{m}^{3}\right)$ \\
\hline 540 & $\varphi$ & volume fraction (1) \\
\hline 541 & $\mu$ & biomass specific growth rate $(1 / \mathrm{h})$ \\
\hline 542 & $\mu_{d}$ & biomass specific decay rate $(\mathrm{L} / \mathrm{g} / \mathrm{h})$ \\
\hline 543 & $\mu_{l}$ & liquid viscosity $(\mathrm{Pa} \cdot \mathrm{s})$ \\
\hline 544 & $\mu_{T}$ & turbulent or eddy viscosity $(\mathrm{Pa} \cdot \mathrm{s})$ \\
\hline 545 & $\sigma$ & surface tension coefficient $(\mathrm{N} / \mathrm{m})$ \\
\hline 546 & $\tau$ & cell absorption coefficient $\left(\mathrm{m}^{2} / \mathrm{g}\right)$ \\
\hline 547 & $\tau_{s}$ & shear stress $(\mathrm{Pa})$ \\
\hline 548 & Subscripts & \\
\hline 549 & $g$ & gas phase \\
\hline 550 & $l$ & liquid phase \\
\hline
\end{tabular}


553 Table 1. Design configurations of sparger used in the study.

554 Table 2. Effects of the different sparger designs on the PBR productivity.

555

\begin{tabular}{|c|c|c|c|}
\hline Sparger design & $\begin{array}{c}\text { Number of } \\
\text { holes }\end{array}$ & $\begin{array}{c}\text { Hole diameter } \\
(\mathrm{mm})\end{array}$ & $\begin{array}{c}\text { Recycling gas flow } \\
\text { rate }(\mathrm{L} / \mathrm{min})\end{array}$ \\
\hline $\mathbf{1}$ & 62 & 1 & 5 \\
\hline $\mathbf{2}$ & 62 & 1 & 20 \\
\hline $\mathbf{3}$ & 122 & 1 & 5 \\
\hline $\mathbf{4}$ & 122 & 1 & 20 \\
\hline $\mathbf{5}$ & 62 & 5 & 20 \\
\hline $\mathbf{6}$ & 62 & 5 & 5 \\
\hline $\mathbf{7}$ & 122 & 5 & 20 \\
\hline $\mathbf{8}$ & 122 & 5 & 5 \\
\hline
\end{tabular}

Table 1. Design configurations of sparger used in the study.

\begin{tabular}{|c|c|c|c|}
\hline Sparger design & $\begin{array}{c}\text { Productive volume } \\
(\mathrm{L})\end{array}$ & $\begin{array}{c}\text { Unproductive or dead } \\
\text { zone volume }(\mathrm{L})\end{array}$ & $\begin{array}{c}\text { Productivity loss } \\
(\%)\end{array}$ \\
\hline $\mathbf{1}$ & 101.29 & 18.69 & 15.59 \\
\hline $\mathbf{2}$ & 45.55 & 74.43 & 62.04 \\
\hline $\mathbf{3}$ & 118.00 & 1.99 & 1.66 \\
\hline $\mathbf{4}$ & 72.41 & 47.58 & 39.65 \\
\hline $\mathbf{5}$ & 107.42 & 12.57 & 10.48 \\
\hline $\mathbf{6}$ & 46.03 & 73.96 & 61.64 \\
\hline $\mathbf{7}$ & 115.83 & 4.16 & 3.475 \\
\hline $\mathbf{8}$ & 79.30 & 40.69 & 33.91 \\
\hline
\end{tabular}

Table 2. Effects of the different sparger designs on the PBR productivity. 


\section{LIST OF FIGURES}

559 Figure 1. Experimental 120 L flat-plate closed photobioreactor (a) and its computational fluid 560 dynamic (CFD) model (b) used in the simulations.

561 Figure 2. Comparison between the experimental and CFD results based on (a) biomass 562 concentration and (b) bisabolene production.

563 Figure 3. Gas bubble volume fraction with different numbers and diameters of sparger holes at 564 different gas recycling rates.

565 Figure 4. Comparison of the CFD data with the empirical correlation of bubble volume fraction 566 for different sparger designs.

567 Figure 5. Friction velocity with different numbers and diameters of sparger holes at different gas 568 recycling rates.

569 Figure 6. Biomass concentration and bisabolene production with different numbers and 570 diameters of sparger holes at different gas recycling rates.

571 


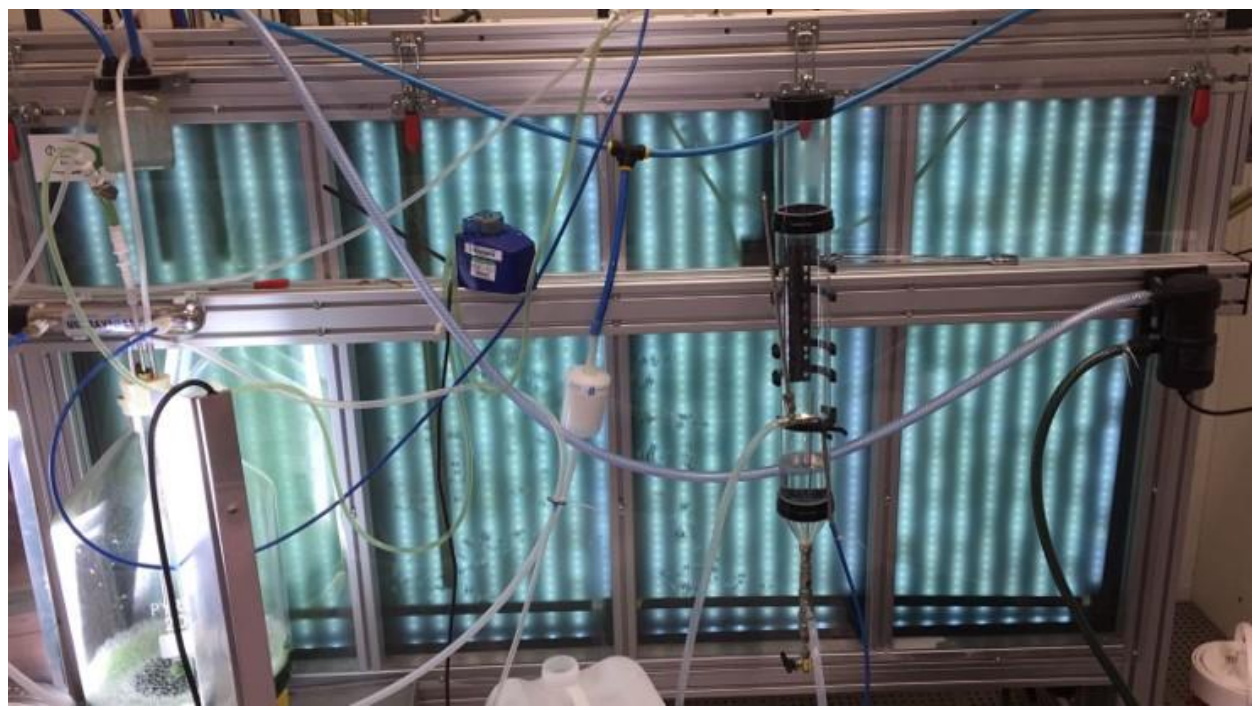

(a)

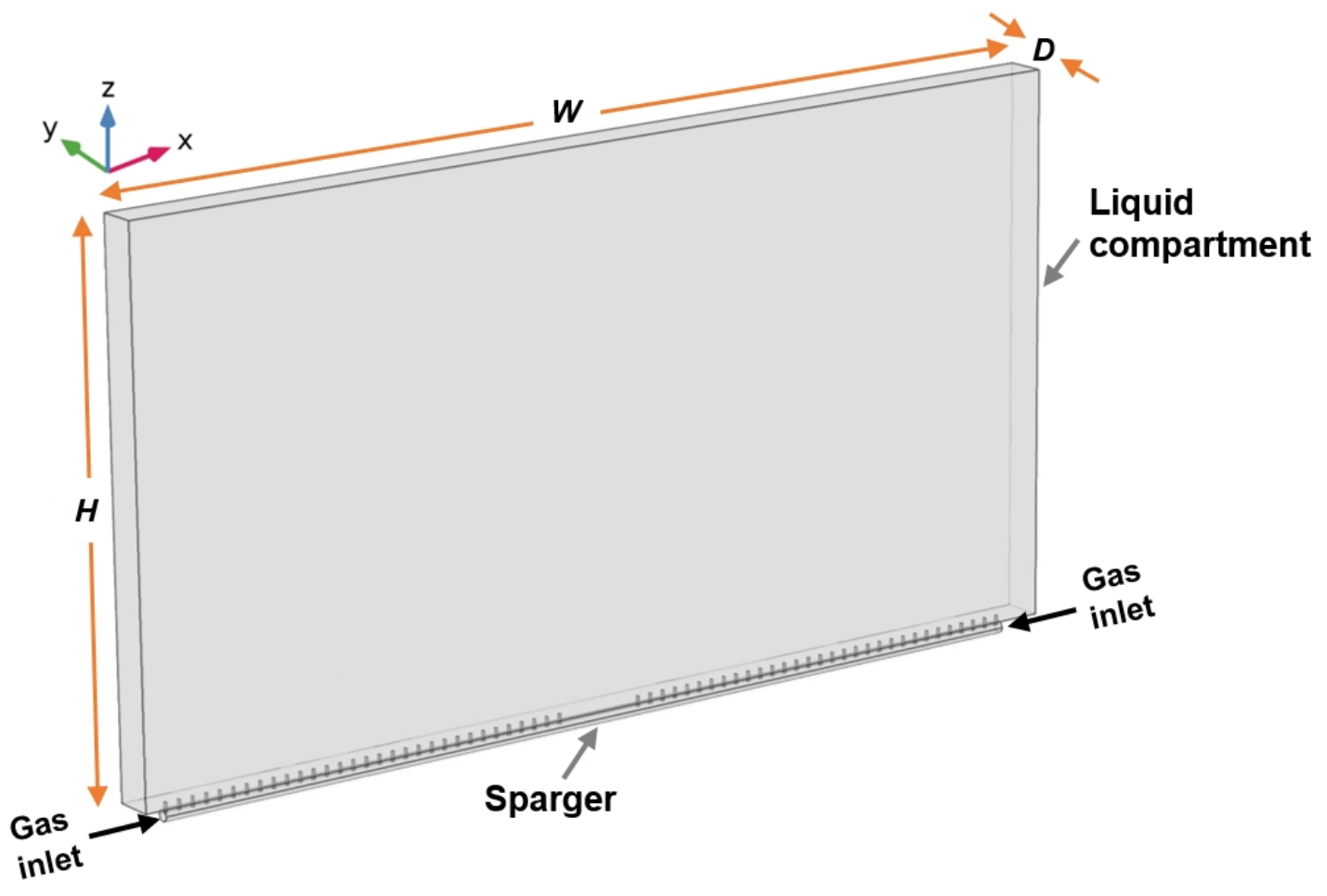

(b)

576 Figure 1. Experimental 120 L flat-plate closed photobioreactor (a) and its computational fluid dynamic (CFD) model (b) used in the simulations. 


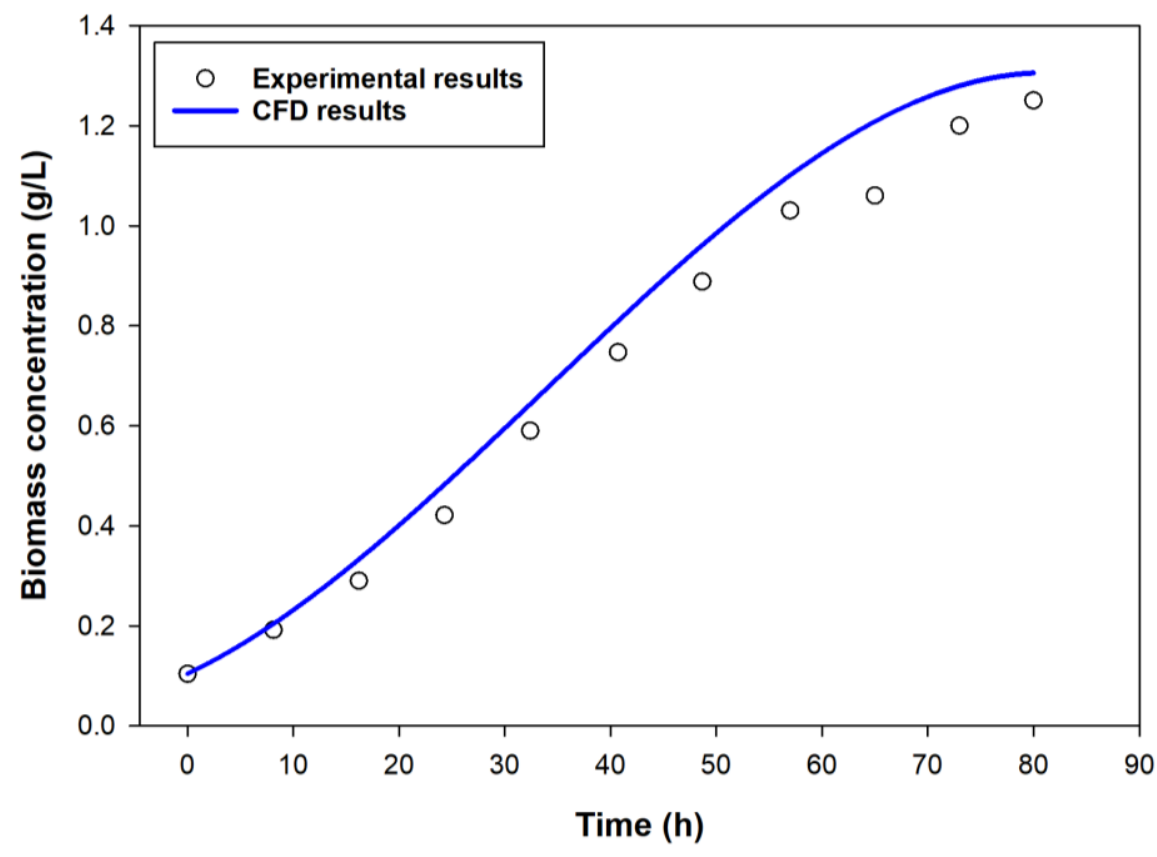

579

(a)

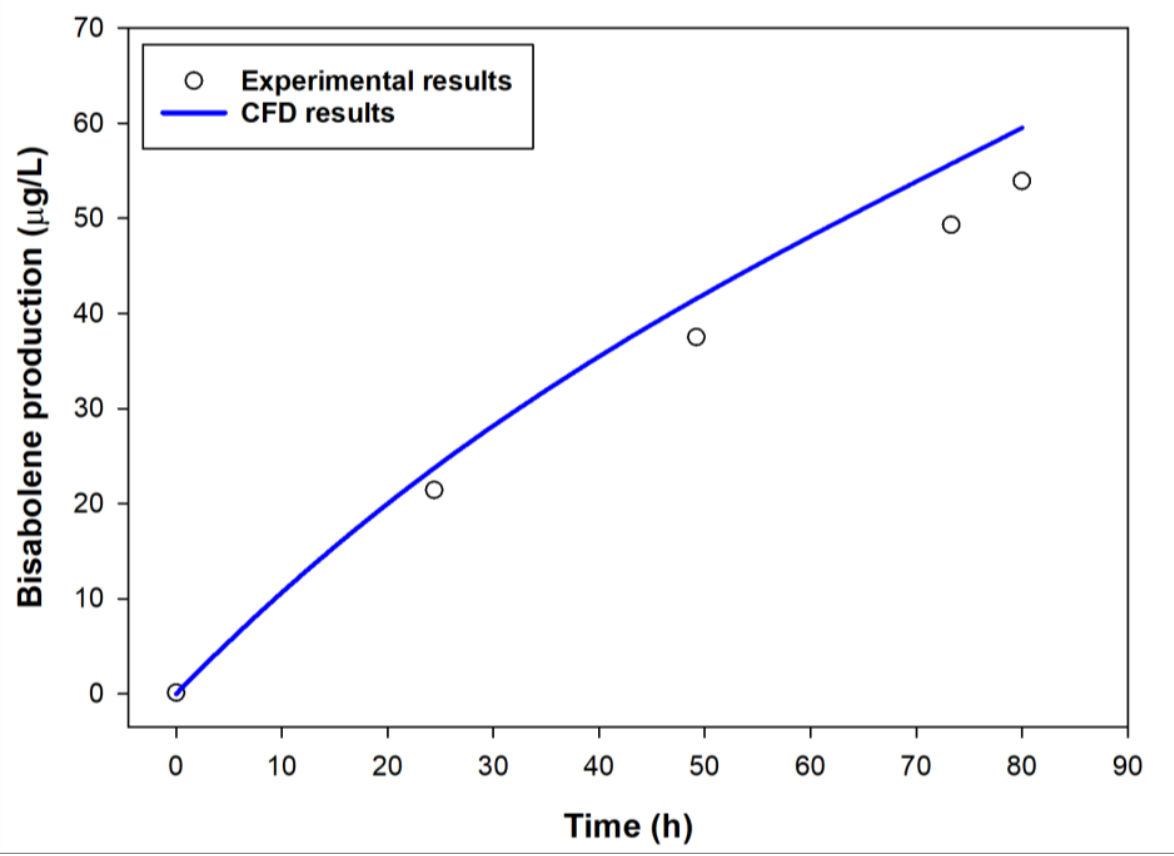

(b)

Figure 2. Comparison between the experimental and CFD results based on (a) biomass concentration and (b) bisabolene production. 

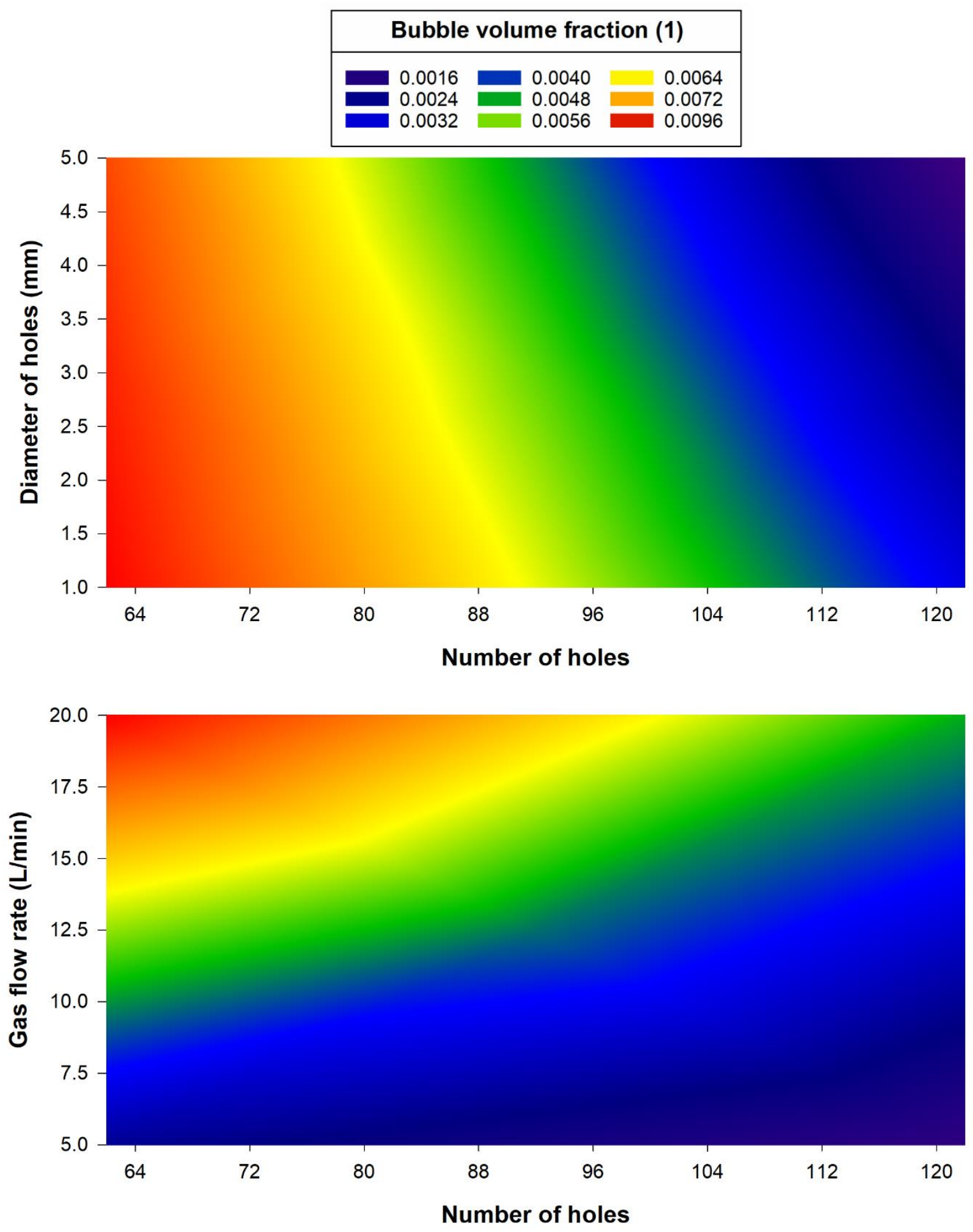

585 Figure 3. Gas bubble volume fraction with different numbers and diameters of sparger holes at 


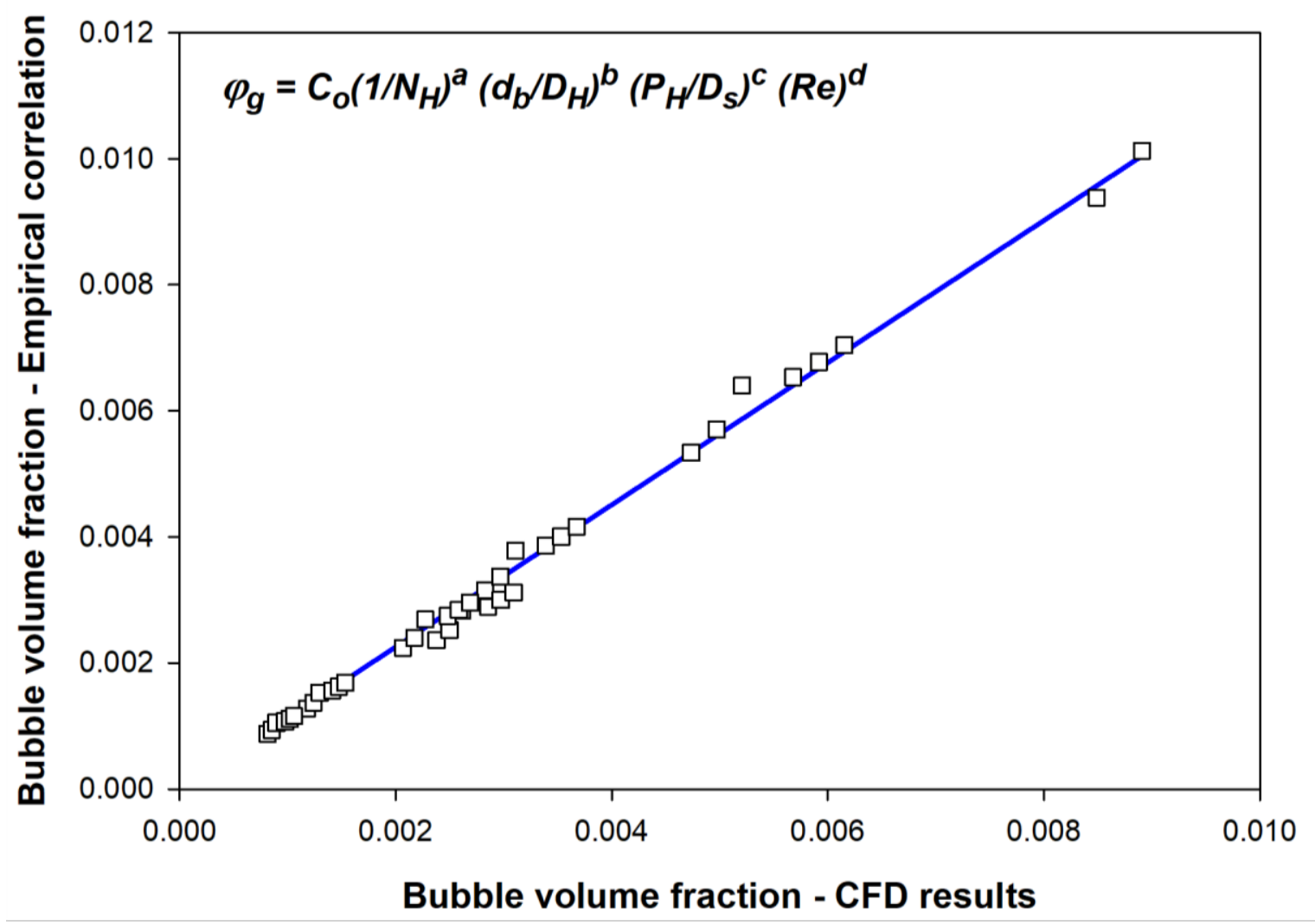

588 Figure 4. Comparison of the CFD data with the empirical correlation of bubble volume fraction 589 for different sparger designs. 

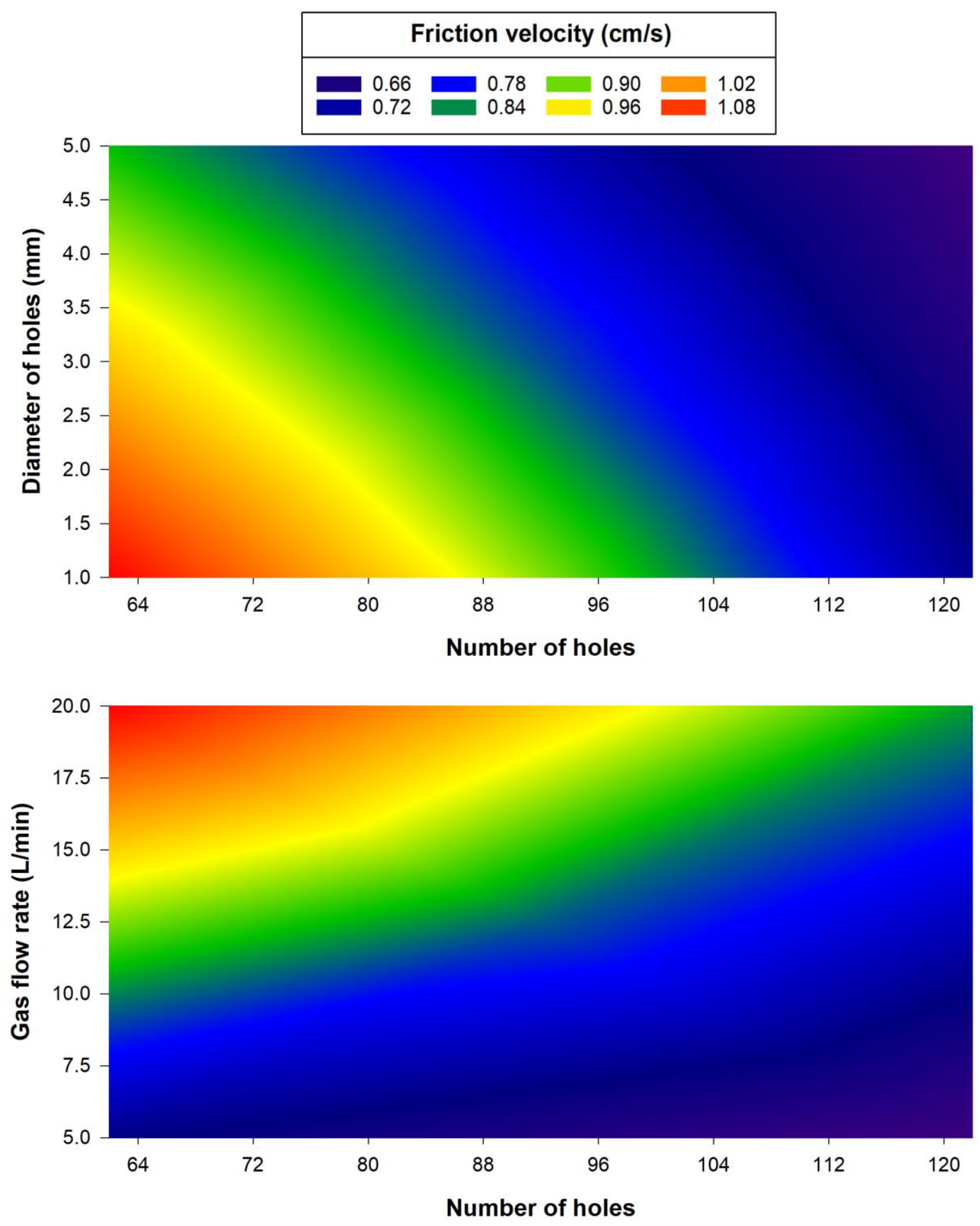

592 Figure 5. Friction velocity with different numbers and diameters of sparger holes at different gas recycling rates. 

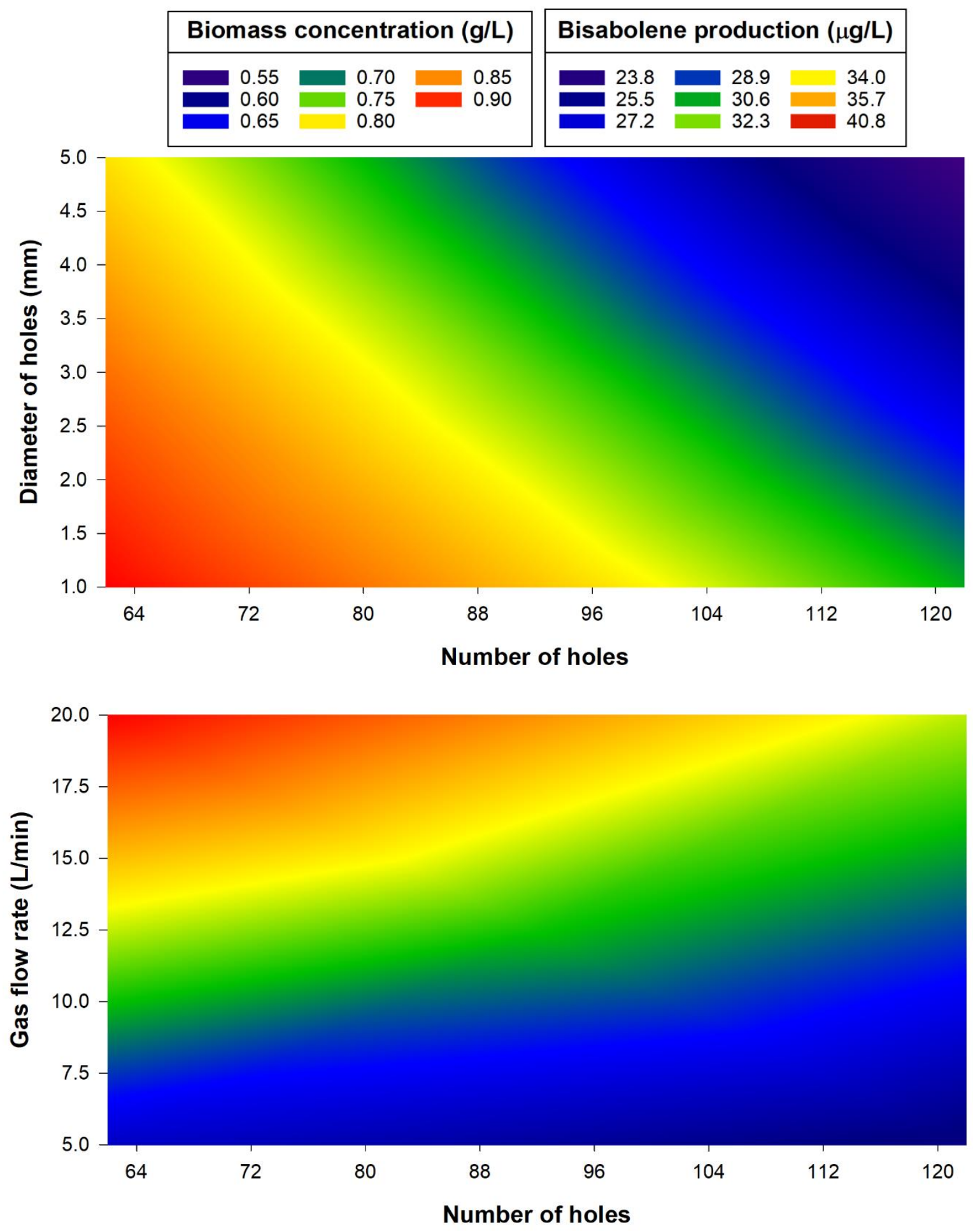

Figure 6. Biomass concentration and bisabolene production with different numbers and diameters of sparger holes at different gas recycling rates. 